\title{
Recanalization of the occluded radial artery via distal transradial access in the anatomic snuffbox
}

\author{
Feng Li ${ }^{1}$, Gan-Wei Shi ${ }^{1}$, Bi-Feng Zhang ${ }^{2}$, Xiao-Long Yu ${ }^{3}$, Hao-Min Huang ${ }^{1}$, Jian-Qiang Xiao ${ }^{1}$ and Gao-Jun Cai ${ }^{*}$ (i)
}

\begin{abstract}
Background: Radial artery occlusion is a common complication after coronary angiography and percutaneous coronary intervention via the transradial access. In recent years, coronary angiography and percutaneous coronary intervention via the distal transradial access has gradually emerged, but recanalization of the occluded radial artery through the distal transradial access has rarely been reported.

Case presentation: A 67-year-old female with arterial hypertension and diabetes mellitus was admitted to the hospital due to chest pain for three hours. She was diagnosed with acute myocardial infarction. After admission, the patient successfully underwent emergency coronary angiography and percutaneous coronary intervention through the right transradial access. Radial artery occlusion was found after the operation, and recanalization was successfully performed through the right distal transradial access before discharge. Immediately after the operation and one month later, vascular ultrasonography showed that the antegrade flow was normal.
\end{abstract}

Conclusions: This report presents a case of radial artery occlusion after emergency coronary angiography and percutaneous coronary intervention in which recanalization was successfully performed through the right distal transradial access. This case demonstrates that recanalization of a radial artery occlusion via the distal transradial access is safe and feasible.

Keywords: Transradial access, Distal transradial access, Anatomic snuffbox, Radial artery occlusion, Case report

\section{Background}

The transradial access (TRA) is currently the routine access for coronary angiography (CAG) and percutaneous coronary intervention (PCI), and radial artery occlusion (RAO) is a common complication [1]. In recent years, the distal transradial access (dTRA) (anatomic snuffbox (AS)) has emerged a new access for CAG and PCI [2], and recognition of its advantage in clinical applications by cardiac interventionists has gradually

\footnotetext{
*Correspondence: cgj982@126.com

${ }^{1}$ Department of Cardiology, Wujin Hospital Affiliated To Jiangsu

University, The Wujin Clinical College of Xuzhou Medical University,

Changzhou 213017, Jiangsu Province, China

Full list of author information is available at the end of the article
}

increased. An increasing number of cardiac intervention centers are trying to use this access for CAG and PCI, but there are fewer reports on its use in recanalization of RAO after CAG and PCI. Recently, we encountered a patient with RAO after PCI, and recanalization of the occluded radial artery was successfully performed through dTRA. The patient provided informed consent for publication of this case. The present study was approved by the Ethics Committee of Wujin Hospital affiliated with Jiangsu University (Ethics Committee number: 2019-31). 


\section{Case presentation}

A 67-year-old female was admitted to the hospital due to chest pain for three hours. She had a history of arterial hypertension for 30 years and diabetes mellitus (DM) for 3 years. ECG showed acute inferior and right ventricular myocardial infarction. After administration of $300 \mathrm{mg}$ aspirin, $180 \mathrm{mg}$ ticagrelor and $5000 \mathrm{U}$ heparin, CAG was carried out emergently via the right TRA. The results showed that there was $60-70 \%$ stenosis in the middle of the right coronary artery, and the distal segment was completely occluded. Then, a $2.5 \times 28 \mathrm{~mm}$ drug-eluting stent was implanted into the distal segment of the right coronary artery. The $6 \mathrm{Fr}$ sheath (Terumo Radifocus) was removed from the radial artery after $25.5 \mathrm{~h}$, and the puncture site was bandaged with gauze for ten hours. On the third day post operation, we found that the pulsation of the artery near the puncture site could not be appreciated during palpation, whereas a weak pulse existed in the distal radial artery in the AS region. We suspected that the radial artery might be occluded. Vascular ultrasonography showed that there was no blood flow near the puncture site. Because the patient had recently undergone right $\mathrm{RAO}$, we decided to recanalize the occlusion via the right dTRA. Therefore, after successful puncture of the distal radial artery in the AS, the radial artery was confirmed to be completely occluded by cannula angiography (Fig. 1). Then, a 6Fr sheath (Terumo Radifocus) was inserted into the distal radial artery, and the tip of the sheath was near the distal segment of the occlusion. After failing to absorb the thrombosis, a Runthrough guidewire was sent through the occluded segment, then we injected

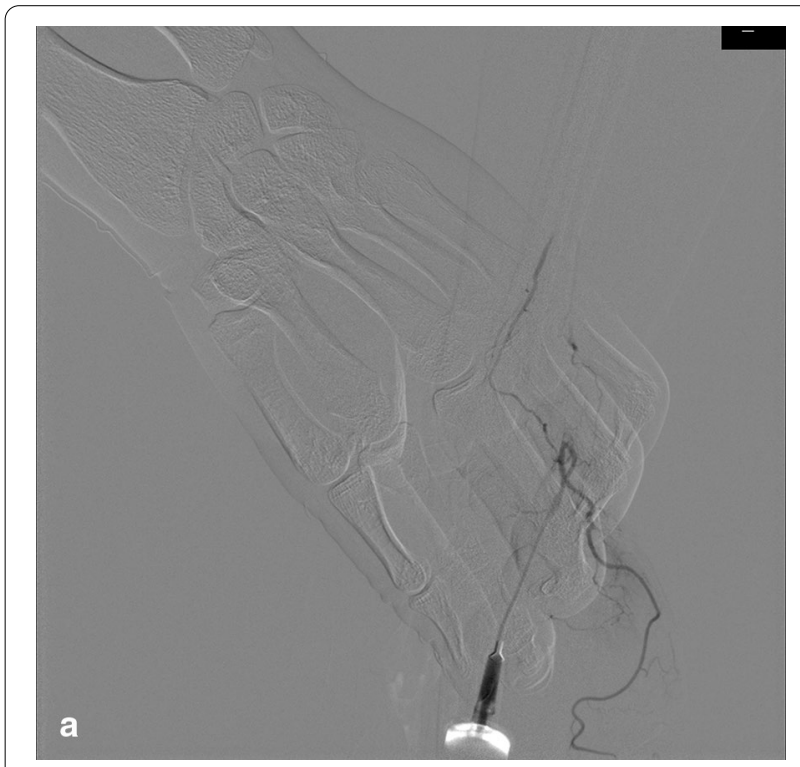

Fig. 1 Angiogram via cannula
$2000 \mathrm{U}$ heparin and $200 \mathrm{ug}$ nitroglycerin through the sheath, and a BRAUN $2.0 \times 20 \mathrm{~mm}$ balloon was used to dilate the occluded segment with $8-10$ atm $\times 1 \mathrm{~min}$ of pressure for several rounds. Repeated angiography showed that the blood flow of the radial artery was resumed (Fig. 2). The distal radial artery puncture site of in the AS was compressed with gauze for four hours. There were no local complications in the AS region after the operation, such as bleeding, swelling and numbness. The pulsation of the right distal radial artery and the radial artery was normal, and vascular ultrasonography showed that the antegrade flow was normal (Fig. 3). The results of vascular ultrasonography follow-up one month after the operation were the same as those immediately after operation.

\section{Discussion and conclusions}

Currently, the TRA has been recommended as a routine pathway for CAG and PCI [1]. Compared with the femoral artery access, PCI via TRA can reduce the incidence of major cardiovascular adverse events and all-cause mortality in patients with acute coronary syndrome [3, 4]. In recent years, RAO has become a common complication in the TRA, which has received increasing attention from interventional cardiologists. Research have shown that the incidence of RAO is $1 \%-12 \%[5,6]$ and can be as high as $30 \%$ [7]. Many factors might be associated with RAO, such as female sex, DM, sheath size, operation time, low body mass index, long compression time, and repeated operation [8]. Due to the dual blood supply, most patients suffering from RAO have no symptoms. However, RAO limits the utilization, such as for repeated CAG and PCI, of the radial artery, which is used as the bypass grafting and arteriovenous fistula vessel.

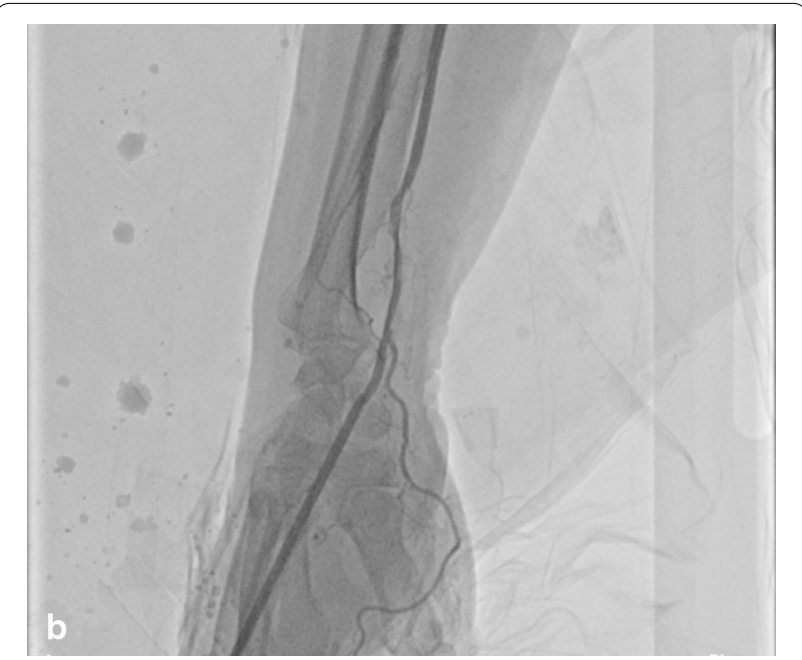

Fig. 2 Angiogram of the radial artery resumed 


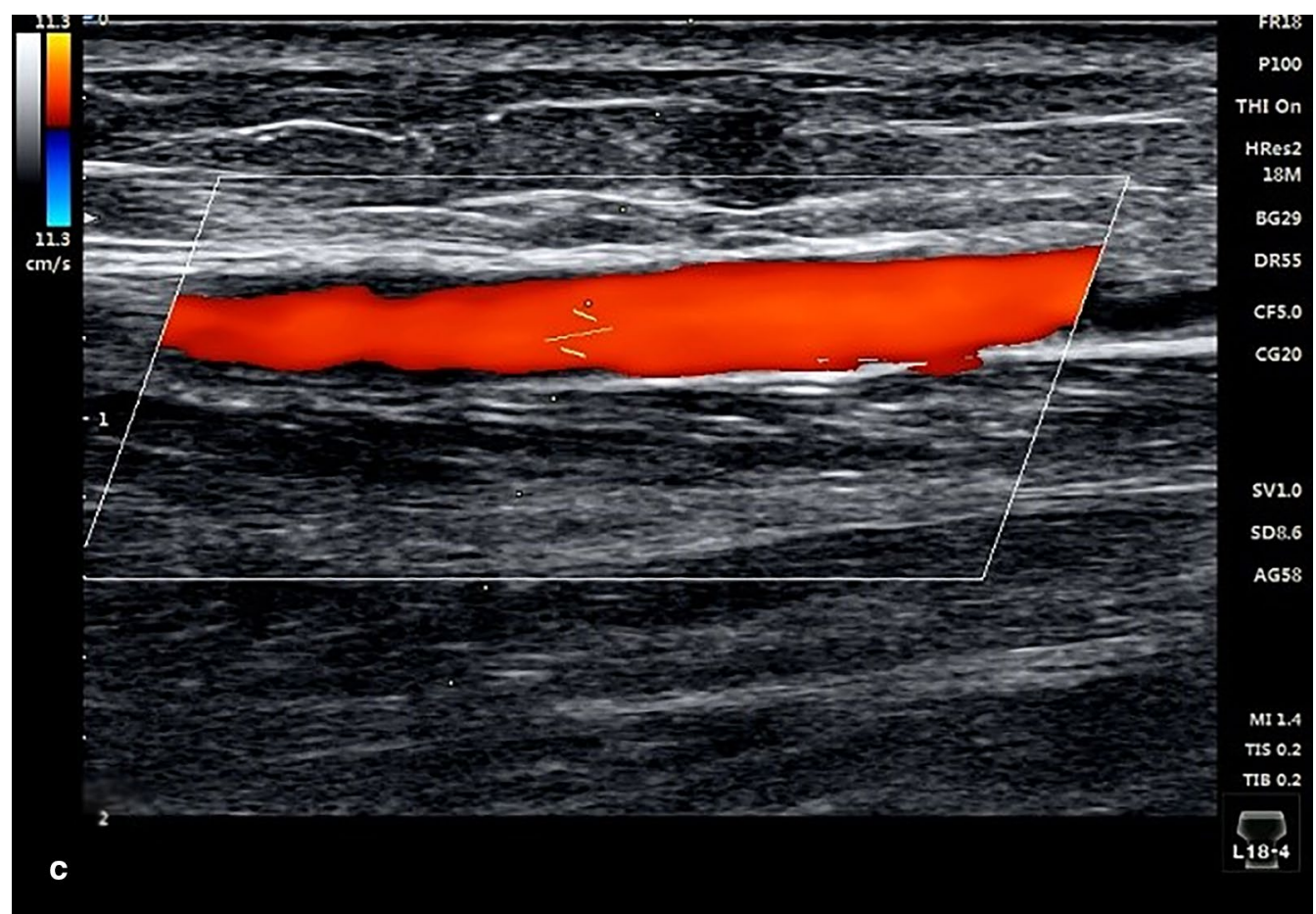

Fig. 3 Ultrasonography of the blood flow resumed in the site of radial artery

Therefore, it has recently become increasingly important to repair RAO. For this case, it was a female with DM and long compression time, which might have contributed to the RAO. In addition, in our center, patients with AMI undergoing emergency PCI routinely retain the sheath for monitoring the intra-arterial pressure after procedure. It is also one of the causes of RAO, but it is our local practice and not widely adopted. We have recognized this problem. Recently, we routinely carried out coronary angiography and intervention via the dTRA in our center. The sheath was removed immediately after the procedure, and the hemostatic time was reduced to 3-4 h, which was significantly shorter than before.

In 2017, the dTRA was first described by Kiemeneij as the alternative access for cardiac catheterization [2]. Since then, the safety and efficacy of CAG and PCI via the ITRA has attracted the attention of cardiologic interventionalists [9-11]. At the same time, some studies have found that it was also safe and feasible to recanalize radial artery stenosis or occlusion via dTRA [12-14]. In 2018, Schulte-Hermes et al. [12] successfully performed angioplasty via dTRA in eight cases with severe radial artery stenosis. Sheikh AR et al. reported their successful experience in recanalizing the left RAO through the left dTRA [13]. Under the guidance of vascular ultrasonography, Alkhawam $\mathrm{H}$ et al. successfully recanalized chronic $\mathrm{RAO}$ in a patient with acute myocardial infarction
(AMI) [14]. We first reported the recanalization of RAO via dTRA in a Chinese patient with AMI. In this case, because the RAO occurred recently, the thrombosis could not be absorbed through the sheath. Therefore, we could easily pass through the occluded segment by using a 0.014" guild wire during the operation and successfully complete the angioplasty. If the radial artery was occluded for a prolonged time, a strong guide wire might be used [13]. Although the radial artery was occluded, pulsation of the distal radial artery could be appreciated in the AS due to the palmar arches and abundant lateral branches [15]. Furthermore, we are experienced in distal radial artery puncture, which provided a guarantee for successfully repairing the RAO. As we know, the distal radial artery was smaller, which increased the difficulty of the puncture, and successful puncture was the first and the key step to ensure completion of the recanalization. To improve the success rate of distal radial artery puncture, we suggest that puncture should be carried out by experienced cardiologists under the guidance of vascular ultrasonography.

\section{Abbreviations}

DM: Diabetes mellitus; AMI: Acute myocardial infarction; ECG: Electrocardiogram; CAG: Coronary angiography; TRA: Transradial access; dTRA: Distal transradial access; AS: Anatomic snuffbox; RAO: Radial artery occlusion; PCI: Percutaneous coronary intervention. 


\section{Acknowledgements \\ Not applicable.}

\section{Authors' contributions}

FL and GWS followed up the patient, performed the literature review, and drafted the manuscript. BFZ, JQX and GJC critically revised the manuscript and assisted in the literature review. XLY and $\mathrm{HMH}$ collected the date and references. All authors read and approved the final manuscript.

\section{Funding}

This study was supported by Jiangsu Youth Medical Talents Project (No. QNRC2016310) and Science and Technology Project of Wujin (No. WS202001). No funding body participated in the design of the study and collection, analysis, and interpretation of data and in writing the manuscript.

\section{Availability of data and materials}

All available information is contained within the present manuscript.

\section{Ethics approval and consent to participate}

Not applicable.

\section{Consent for publication}

Written informed consent was obtained from the patient for publication of this case report and any accompanying images. A copy of the written consent is available for review by the Editor of this journal.

\section{Competing interests}

Gaojun Cai is a member of the editorial board of BMC Cardiovascular Disorders. The other authors declare that they have no competing interests.

\section{Author details}

1 Department of Cardiology, Wujin Hospital Affiliated To Jiangsu University, The Wujin Clinical College of Xuzhou Medical University, Changzhou 213017, Jiangsu Province, China. ${ }^{2}$ Department of Pathology and Molecular Medicine, McMaster University, Hamilton, ON L8S4L8, Canada. ${ }^{3}$ Department of Ultrasonic, Wujin Hospital Affiliated To Jiangsu University, The Wujin Clinical College of Xuzhou Medical University, Changzhou 213017, Jiangsu Province, China.

Received: 10 September 2020 Accepted: 25 January 2021

Published online: 02 February 2021

\section{References}

1. Neumann FJ, Sousa-Uva M, Ahlsson A, et al. 2018 ESC/EACTS Guidelines on myocardial revascularization. Eur Heart J. 2019;40(2):87-165.

2. Kiemeneij F. Left distal transradial access in the anatomical snuffbox for coronary angiography (IdTRA) and interventions (IdTRI). Eurolntervention. 2017;13(7):851-7.
3. Valgimigli M, Gagnor A, Calabró P, et al. Radial versus femoral access in patients with acute coronary syndromes undergoing invasive management: a randomisedmulticentre trial. Lancet. 2015;385(9986):2465-76.

4. Ferrante G, Rao SV, Jüni P, et al. Radial versus femoral access for coronary interventions across the entire spectrum of patients with coronary artery disease: a meta-analysis of randomized trials. JACC Cardiovasc Interv. 2016:9(14):1419-34.

5. Kotowycz MA, Dzavík V. Radial artery patency after transradial catheterization. Circ Cardiovasc Interv. 2012:5(1):127-33.

6. Rashid M, Kwok CS, Pancholy S, et al. Radial artery occlusion after transradialinterventions: a systematic review and meta-analysis. J Am Heart Assoc. 2016;5(1):e002686.

7. Uhlemann M, Möbius-Winkler S, Mende M, et al. The Leipzig prospective vascular ultrasound registry in radial artery catheterization: impact of sheath size on vascular complications. JACC Cardiovasc Interv. 2012:5(1):36-43.

8. Rao SV, Tremmel JA, Gilchrist IC, et al. Best practices for transradial angiography and intervention: a consensus statement from the society for cardiovascular angiography and intervention's transradial working group. Catheter Cardiovasc Interv. 2014:83(2):228-36.

9. Amin MR, Banerjee SK, Biswas E, et al. Feasibility and safety of distal transradial access in the anatomical snuffbox for coronary angiography and intervention. Mymensingh Med J. 2019;28(3):647-54.

10. Maitra S, Ray BR, Bhattacharjee S, Baidya DK, Dhua D, Batra RK. Distal radial arterial cannulation in adult patients: a retrospective cohort study. Saudi J Anaesth. 2019;13(1):60-2.

11. Koutouzis M, Kontopodis E, Tassopoulos A, et al. Distal versus traditional radial approach for coronary angiography. Cardiovasc Revasc Med. 2019:20(8):678-80

12. Schulte-Hermes M, Klein-Wiele O, Vorpahl M, Seyfarth M. Feasibility of transradial access for coronary interventions via percutaneous angioplasty of the radial artery in cases of functional radial occlusion. J Invasive Cardiol. 2018;30(10):355-9.

13. Sheikh AR, Abdelaal E, Sastry S, Karim S, Zeb M. Novel distal left radial artery access in anatomical snuffbox for recanalization of proximal radial artery total occlusion and percutaneous coronary intervention through left internal mammary artery. Circ Cardiovasc Interv. 2018;11(7):e006579.

14. Alkhawam H, Windish S, Abo-Salem E. Distal radial artery access among cases with radial artery occlusion for primary percutaneous intervention. Future Cardiol. 2019;15(3):169-73.

15. Sgueglia GA, Di Giorgio A, Gaspardone A, Babunashvili A. Anatomic basis and physiological rationale of distal radial artery access for percutaneous coronary and endovascular procedures. JACC Cardiovasc Interv. 2018:11(20):2113-9.

\section{Publisher's Note}

Springer Nature remains neutral with regard to jurisdictional claims in published maps and institutional affiliations.

Ready to submit your research? Choose BMC and benefit from:

- fast, convenient online submission

- thorough peer review by experienced researchers in your field

- rapid publication on acceptance

- support for research data, including large and complex data types

- gold Open Access which fosters wider collaboration and increased citations

- maximum visibility for your research: over $100 \mathrm{M}$ website views per year

At BMC, research is always in progress.

Learn more biomedcentral.com/submissions 